\title{
MÍDIA NA MIRA: JULGAMENTOS E DISCURSOS DE ÓDIO \\ DISSEMINADOS POR HASHTAG NO TWITTER
}

\author{
MEDIA IN TARGET: JUDGMENTS AND HATE DISCOURSE \\ DISSEMINATED BY A HASHTAG ON TWITTER
}

\author{
Karen Tank Mercuri (Unicamp) \\ k001935@dac.unicamp.br
}

\begin{abstract}
RESUMO: Este artigo tem como objetivo analisar os comentários no Twitter que acompanharam a hashtag \#FolhaPutinhaDoPT, em 2018, buscando entender o comportamento de parte da população em relação à imprensa. Os aportes teóricometodológicos eleitos foram o Sistema da Avaliatividade (MARTIN; WHITE, 2005) e a Gramática do Design Visual (KRESS; VAN LEEUWEN, 1996) para verificar atitudes avaliativas em textos tanto verbais como visuais ou, ainda, avaliações oriundas da junção de semioses. Em termos de Avaliatividade, os julgamentos predominantes em relação ao jornal foram de veracidade e de propriedade, porque, na visão dos enunciadores, a notícia contestada não era verdadeira e o jornal estaria recebendo dinheiro do partido adversário para publicá-la. $O$ afeto predominante foi de infelicidade, com gradações que levaram o sentimento de não-gostar ao nível do detestar. O uso de imagens, na maioria dos casos, funcionou como recurso de gradação, dando maior força argumentativa ao texto verbal que introduzia as postagens.
\end{abstract}

PALAVRAS-CHAVE: mídia; avaliatividade; multimodalidade; discurso de ódio.

ABSTRACT: This article aims to analyze the comments on Twitter that accompanied the hashtag \#FolhaPutinhaDoPT, in 2018, in order to understand the behavior of part of the population in relation to the press. The theoretical-methodological contributions chosen were the Appraisal Discourse (MARTIN; WHITE, 2005) and the Grammar of Visual Design (KRESS; VAN LEEUWEN, 1996), to verify evaluative attitudes in both verbal and visual texts, or still, evaluations coming from the junction of semioses. Regarding the appraisal discourse, the predominant judgment in relation to the newspaper were veracity and propriety, because, in the opinion of the enunciators, the contested news was not true, and the newspaper would be receiving money from the opposing political party to publish it. The predominant Affect was unhappiness, with gradations ranging from the level of disliking to the level of detesting. The use of images, in most cases, functioned as a graduation resource, providing greater argumentative strength to the verbal text that introduced the posts. 
KEYWORDS: media; appraisal; multimodality; hate discourse.

\section{Introdução}

No atual cenário político do Brasil, vem ganhando força uma narrativa que coloca em dúvida o papel da imprensa. Mais que isso, transforma-a em inimiga da nação. Palavras ou expressões de ataque à imprensa tomam grandes proporções ao serem compartilhadas na Internet. Uma das estratégias tem sido utilizar uma hashtag padrão e torná-la o assunto mais falado no momento. As hashtags, "que são elementos bastante marcados na cibercultura atual, assumem então aspectos singulares, próprios da plataforma e da intencionalidade dos usuários" (CORDEIRO, 2020, p. 261). Influenciadores digitais, ativistas e políticos procuram fortalecer suas redes de apoio por meio de postagens de hashtags criadas para determinado fim. As hashtags não são só um marco histórico-social, mas também um objeto de estudo bastante interessante - como nos trabalhos de Lima-Lopes e Gabardo (2019) e Mercuri e Lima-Lopes (2020), entre outros -, pois possibilitam indexar vários comentários, contribuindo para análises em larga escala, monitoramento de padrões linguísticos, acompanhamento de processos etc.

Além disso, elas também configuram uma nova prática linguística, pois passaram por um processo de gramaticalização, o qual ocorre quando, em determinado contexto linguístico, um item primitivamente lexical passa a servir a (novas) funções gramaticais (HOPPER; TRAUGOTT, 1993). Assim, no processo de gramaticalização de uma hashtag, as motivações discursivas fazem com que um item, originalmente pensado para facilitar a busca e o engajamento, passe a integrar a oração (como sujeito, vocativo, complemento verbal/nominal). Por isso, em muitos casos as hashtags são indissociáveis dos comentários que as acompanham (LIMA-LOPES; MERCURI; GABARDO, 2020).

Para este artigo, são estudados comentários coletados do Twitter, que continham a hashtag \#FolhaPutinhadoPT, a qual traz em si, simultaneamente, um julgamento a um veículo de comunicação e a um partido político, bem como expressão de sentimento da ordem do não-gostar. Como em um estudo da língua deve-se levar em consideração contextos de uso e o grupo de falantes (HALLIDAY, 1994), faz-se necessário descrever o seu contexto de situação.

Em outubro de 2018, próximo ao segundo turno das eleições presidenciais no Brasil, o jornal Folha de S. Paulo publicou uma matéria revelando que um grupo de empresários 
estaria firmando contratos milionários para disparos de fake news, por WhatsApp, contra o Partido dos Trabalhadores, o PT, com o intuito de alavancar a campanha de Bolsonaro (MELLO, 2018). Tais contratos foram considerados ilegais, "caixa 2 eleitoral"1 (MOISÉS, 2010), porque a doação de recursos financeiros por empresas para campanhas eleitorais, além de não ser declarada, é vedada pela legislação eleitoral. Logo após a publicação, a jornalista que assinou a matéria sofreu vários ataques na Internet. Além dela, o jornal também sofreu retaliações nas mídias sociais. No Twitter, uma hashtag foi criada com o nome \#FolhaPutinhadoPT e disseminada para esse fim.

Contudo, o discurso de ódio em mídias sociais é apenas uma parte do linchamento virtual (MACEDO, 2018), pois as ofensas, humilhações e punições não se limitam ao ambiente online; pelo contrário, sempre há consequências fora das redes, seja por ofensas verbais, seja por agressão física. Ao tecer a ideia de imprensa como inimiga do povo, como seria o comportamento da sociedade sem acreditar nas informações dos meios oficiais? Como jornais e jornalistas seriam tratados? Essas questões motivaram a coleta de dados, em 2018, para este trabalho, que também contou com a observação de fatos durante os anos subsequentes ao da pesquisa.

Já durante o mandato presidencial de Jair Bolsonaro (2019-atual), foram noticiadas situações desmerecendo a credibilidade da imprensa, tais como as ofensas na fala do presidente que foram/são ecoadas por seus apoiadores nas mídias sociais. Como ataque à imprensa, pode-se relatar o episódio de maio de 2020, em frente ao palácio Alvorada, quando o presidente chama a própria Folha de S. Paulo de "imprensa canalha" e "jornal patife e mentiroso" (DELLA COLETTA, 2020). Na mesma situação, o presidente disse algumas vezes: "cala a boca", aos jornalistas que tentavam interrogá-lo. A impolidez com os profissionais também pode ser exemplificada nesta frase dita pelo presidente a um repórter, em agosto de 2020: "Minha vontade é encher tua boca na porrada" (SENRA, 2020), quando questionado sobre os depósitos suspeitos na conta de sua esposa. Nas mídias sociais, sobretudo no Twitter, apoiadores de Jair Bolsonaro usaram a frase dita por ele, para apoiar e incentivar agressões aos jornalistas, não só em ataques verbais, mas também em ameaças

\footnotetext{
${ }^{1}$ Para Speck (2006), o financiamento de campanha eleitoral "envolve recursos materiais empregados pelos competidores em eleições populares (partidos e candidatos) para organizar a campanha e convencer os cidadãos a lhes conferirem o voto" (SPECK, 2006, p. 153). O recebimento de recursos, bem como a sua declaração, deve estar de acordo com o disposto no Código Eleitoral brasileiro. Assim, os gastos eleitorais não contabilizados, ou seja, o uso de recursos privados movimentados paralelamente à contabilidade exigida pela legislação, configurase em "caixa 2 eleitoral” (MOISÉS, 2010). O maior dano do caixa 2 eleitoral é justamente o uso político desses valores, já que empresas doam altas quantias para campanhas a fim de se beneficiarem caso o candidato apoiado seja eleito. Para evitar esse tipo de conduta, a Lei Eleitoral do Brasil não permite que pessoas jurídicas (empresas) façam doações de valores para campanhas eleitorais.
} 
concretas de violência física. Um exemplo pode ser visto na Figura 1.

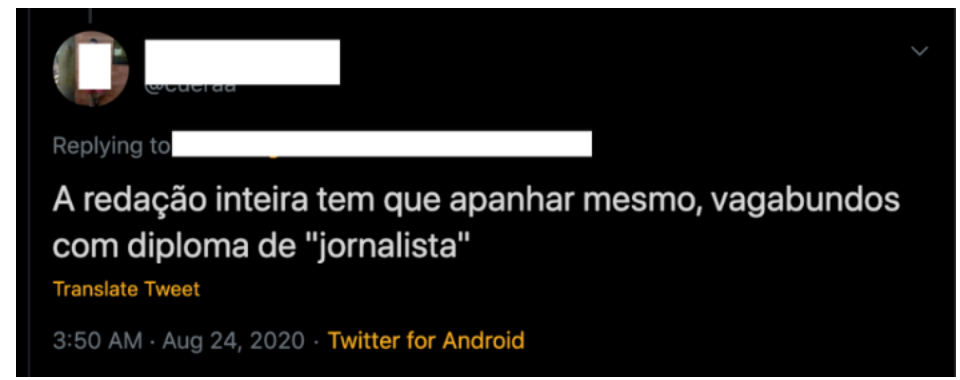

Figura 1 - tuíte contra jornalistas

Fonte: Senra, 2020

Dada a recorrência dos ataques à imprensa, confirmados no relatório da Associação Brasileira de Emissoras de Rádio e Televisão (ABERT) ${ }^{2}$, em 2020, e o risco que essa atitude pode causar ao Estado Democrático de Direito, considera-se importante focar na função avaliativa da linguagem (THOMPSON; ALBA-JUEZ, 2014) a fim de se ter uma dimensão de como foram/são construídos os insultos à imprensa. Mais especificamente, pretende-se resgatar a base de dados da época da campanha eleitoral, oriunda da coleta feita pela hashtag \#FolhaPutinhadoPT, e analisar os comentários tanto verbais como verbo-visuais que acompanharam essa hashtag.

Para essas análises, será utilizado como suporte teórico-metodológico os pressupostos da Linguística Sistêmico-Funcional (HALLIDAY, 1994; HALLIDAY; MATTHIESSEN, 2004) e de seus desdobramentos, como o sistema de Avaliatividade (MARTIN; WHITE, 2005) e Multimodalidade (KRESS; VAN LEEUWEN, 1996). Como a hashtag pesquisada é por si avaliativa, considera-se importante entender como se constroem os afetos e julgamentos e de quais tipos eles são. Além disso, por ser a base desta pesquisa um meio digital, em que a imagem é bastante utilizada, a ótica da multimodalidade é complementar a nossa análise linguística. Os referenciais teóricos serão apresentados no próximo tópico.

\section{Análise linguística e multimodal}

Como dito anteriormente, os aportes teóricos deste artigo são o sistema da Avaliatividade (MARTIN; WHITE, 2005) e a Gramática do Design Visual (KRESS; VAN

\footnotetext{
${ }^{2}$ Segundo relatório da ABERT, em 2020, houve registro de um assassinato e 150 casos de violência não letal a 189 profissionais e veículos de comunicação. Em ralação aos ataques virtuais, incluindo menções com expressões depreciativas, como golpista, lixo, parcial, canalha e grande mídia, foram publicados 2,9 milhões de posts, o que configura 6 agressões por minuto. (ABERT, 2021).
} 
LEEUWEN, 1996), ambos apoiados na perspectiva sociossemiótica instaurada pela Linguística Sistêmico-Funcional (HALLIDAY, 1994; HALLIDAY; MATTHIESSEN, 2004).

A Linguística Sistêmico-Funcional, doravante LSF, é uma teoria geral do funcionamento da linguagem, que fornece descrições sobre o como e o porquê de a língua poder variar em função de contextos de uso e em relação ao grupo de falantes. Segundo a LSF, a linguagem seria, então, um sistema de construção de significados baseados nas escolhas que o falante/escritor faz, perante as que ele deixa de fazer, em uma determinada prática discursiva. Essas escolhas do falante/escritor vão se refletir em fatores ideológicos, culturais e sociais em contextos imediato e de cultura (LIMA-LOPES, 2012) e serão materializadas no texto. Dessa maneira, o que é realizado no nível da léxico-gramática reflete no nível semântico-discursivo. Muitas dessas escolhas são feitas para construir avaliações sobre pessoas ou coisas do mundo, e é este o foco deste artigo.

\subsection{A Gramática do Design Visual}

Como a linguagem verbal não é a única semiose presente nos comentários do Twitter, faz-se necessário buscar aportes teórico-metodológicos para desenredar como os recursos visuais de sentido são empregados pelos escritores para alcançarem determinados efeitos em suas audiências (J EWITT; KRESS, 2008). Para isso, será utilizada neste artigo a Gramática do Design Visual - GDV (KRESS; VAN LEEUWEN, 1996), cuja base assenta-se na LSF, a qual entende o texto (tanto verbal como multissemiótico) como um conjunto de signos socialmente compartilhados, utilizados para representar experiências pessoais e negociar relações entre as pessoas.

Kress e van Leeuwen (1996) adaptam as três metafunções propostas por Halliday (1994) e Halliday e Matthiessen (2004) - ideacional, interpessoal e textual - para a leitura visual, a fim de estabelecer parâmetros para a análise de textos multimodais. Na GDV, essas metafunções passam a ser denominadas: função de representação, função de interação e função composicional, as quais serão brevemente descritas a seguir.

$\mathrm{Na}$ função de representação, as imagens representam a experiência por narrativas ou por conceitos. A representação por narrativa descreve um evento e tem como elementos: i) participantes (humanos ou não); ii) vetores indicando ação e reação; iii) um pano de fundo, indicando as circunstâncias de tempo e espaço, podendo também ser representado por balões de pensamento ou diálogo, cadeia de processos ou ainda simbolismos geométricos. $\mathrm{Na}$ representação conceitual, o foco são os atributos e as identidades dos participantes, e as 
características são: i) agrupamento em categorias desses participantes (classificacional); ii) apresentação destes em relação à parte/todo (analítico), o Portador podendo ser atributo ou signo (simbólico); iii) ausência de vetores e/ou do pano de fundo para realçar os participantes e seus atributos.

Já na função de interação, as imagens representam o relacionamento entre os participantes nelas representados e o seu leitor. Dentro dessa análise, deve-se procurar indícios de: i) contato - olhar do participante da imagem em relação ao leitor; ii) distância social - se o participante representado se aproxima ou se distancia do público leitor; iii) atitude - o ângulo formado entre o corpo do participante e o do leitor no eixo vertical; iv) poder - o ângulo formado entre o corpo do participante e o do leitor no eixo horizontal.

Por sua vez, a função composicional descreve a disposição dos elementos representados na imagem conforme o espaço que ocupam no todo. Essa função também leva em consideração a combinação de linguagem verbal e imagem, e seus três aspectos principais são: i) valor da informação, definido de acordo com o posicionamento dos elementos (baseado na leitura ocidental), podendo ser esquerda/direita (Dado/Novo), em cima/embaixo (Ideal/Real) ou ainda Centro/Margem; ii) saliência: estratégia para dar maior ou menor destaque a certos elementos no tex to visual (tamanho, nitidez, primeiro plano, cor etc.); iii) enquadramento: os elementos que compõem a imagem podem estar representados como interligados, separados ou segregados, dependendo das molduras naturais ou produzidas nas imagens.

Assim, diferentemente da linguagem verbal, em que a escolha é representada por classes de palavras e construções sintáticas, na comunicação visual, dentro da perspectiva da semiótica social, as análises voltam-se para a escolha de cor, perspectivas, linhas, posição dos elementos na imagem, construção verbal e/ou verbo-visual etc., implicando a construção do significado. Essas escolhas são instanciações de articulações políticas, posições ideológicas e relações de poder (NASCIMENTO; BEZERRA; HERBELE, 2011).

\subsection{Sistema de Avaliatividade}

As escolhas linguísticas servem, muitas vezes, para a avaliação de pessoas, coisas, fenômenos em comunidade e no mundo. Essas marcas avaliativas instanciadas nos textos podem indicar aprovação/desaprovação, carinho/ódio, elogio/crítica em relação aos seres e aos fatos do contexto social (HALLIDAY, 1994). Nessa direção, Martin e White (2005) propõem o sistema de Avaliatividade, que, seguindo os preceitos da LSF, estabelece 
subsistemas de análise linguística, em que essas marcas avaliativas possam ser agrupadas e categorizadas.

Para o escopo deste artigo, utilizou-se apenas uma pequena parte do complexo sistema de Avaliatividade, o qual possui três grandes subsistemas: atitude, gradação e engajamento. $\mathrm{O}$ subsistema da atitude atende ao escopo deste trabalho, visto que abrange as avaliações do mundo expressas na linguagem. Os campos semânticos do subsistema atitude são: julgamento, o qual é voltado para a avaliação das ações humanas; afeto, que corresponde à avaliação de sentimentos humanos; e apreciação, a qual atribui valor às coisas e aos fenômenos.

Segundo Ikeda, o julgamento "significa a linguagem que critica ou elogia, condena ou aplaude o comportamento - as ações, feitos, ditos, crenças, motivações de um ser ou grupo de seres humanos" (IKEDA, 2010, p. 172). As avaliações de julgamento podem ser de duas naturezas: estima ou sanção social. A primeira refere-se aos julgamentos que podem levar o indivíduo a ser elevado ou rebaixado na estima de sua comunidade, de acordo com valores e crenças; já a segunda envolve alguns conjuntos de regras ou regulamentos, que podem ser morais ou legais, codificados explícita ou implicitamente por uma cultura. Ao quebrá-los, o indivíduo sofre uma sanção (WHITE, 2004).

A estima social abrange três categorias: normalidade, capacidade e tenacidade. A sanção social, por sua vez, engloba duas categorias: veracidade e propriedade. São esses cinco parâmetros que serão utilizados nas análises deste artigo. Normalidade envolve o julgamento de atitudes como estranhas, pouco usuais ou inesperadas; capacidade avalia quão capaz alguém é (física ou intelectualmente); tenacidade diz respeito a quão resoluto, determinado é o indivíduo avaliado; veracidade está ligada à sinceridade, honestidade; por fim, a propriedade diz respeito aos princípios éticos.

O afeto, por seu turno, recobre outros três subsistemas: felicidade, satisfação e segurança, podendo apresentar aspectos positivos ou negativos. A (in)felicidade engloba emoções de alegria ou tristeza; também pode expressar um gostar ou não de alguém (ou de algo). A (in)segurança envolve sentimento de proteção, de estar seguro ou não em relação a alguém ou qualquer coisa no mundo. A (in)satisfação diz respeito às emoções relacionadas a conseguir alcançar (ou não) um objetivo.

Por perpassar os outros sistemas, atribuindo intensidade e/ou enfoque, considera-se importante também levar em consideração o subsistema de gradação, dentro do escopo do sistema de Avaliatividade (MARTIN; WHITE, 2005). Nesse subsistema o significado experiencial mescla-se com o interpessoal. O subsistema de gradação está dividido em duas 
categorias: força e foco, sendo que a "força gradua qualidades, enquanto o foco gradua categorias semânticas prototípicas, em princípio, não suscetíveis de graduação" (NUNES; CABRAL, 2013, p. 254).

A gradação de força refere-se ao modo como se intensificam ou se quantificam as avaliações. Em textos verbais, a quantificação se consolida com itens léxico-gramaticais imprecisos ("pouco", "muitos", "alguns") ou por expressões como "uma grande quantidade de", “em torno de x (pessoas)" etc. Já a intensificação pode ser instanciada em adjetivos, advérbios, verbos e repetições, a exemplo de "intenso", "extremamente", "odiar", "triste, triste, triste" (NUNES; CABRAL, 2017). Já a gradação por foco faz referência a um membro dentro de uma categoria (se marginal ou prototípico). Pode estar no texto verbal como adjetivos ("genuíno", “exemplar”), advérbios (“verdadeiramente", “fielmente”) ou expressões ("um tipo de", "uma espécie de").

Como o corpus analisado apresenta algumas imagens, é interessante observar também como as atitudes de julgamento, acompanhadas ou não de instâncias gradativas, aparecem em textos visuais. Sendo assim, além das contribuições de Martin e White (2005) sobre Avaliatividade e de Kress e van Leeuwen (1996) sobre análise de imagens, também será considerado o trabalho de Florek $(2017)^{3}$, sobretudo o que considera a gradação em imagens, pois as escolhas visuais, como de ângulo e posição, podem aumentar ou diminuir a força ou impacto de um item de representação em uma imagem, interferindo não só em significados interpessoais como também em significados ideacionais.

O sistema de gradação em imagens, segundo Florek (2017), é representado de duas maneiras: i) pelo foco - expressão visual textual: luz, cor e escolhas de foco, semelhante aos recursos de saliência (KRESS; VAN LEEUWEN, 1996); e ii) pela força - expressão visual espacial: ângulos e tamanho do quadro da câmera, tal como no sistema de atitude, da função de interação (KRESS; VAN LEEUWEN, 1996).

O campo semântico do foco visa manter a atenção do espectador. Assim, em imagens, o foco pode estar onde há uma carga maior de informação visual de um determinado item, permitindo a categorização mais precisa desse elemento (FLOREK, 2017). Já a força pode estar representada pela escalonação de um item (do menor para o maior ou vice-versa), pela intensificação (do mais escuro para o mais brilhante) e pela repetição de itens representacionais semelhantes na imagem (FLOREK, 2017).

Partindo da hipótese de que a imagem pode funcionar como recurso de gradação para

\footnotetext{
${ }^{3}$ Baseado nos estudos de Economou (2009). 
o texto verbal, direcionando o foco ou aumentando a força argumentativa, na análise do corpus deste trabalho procurar-se-á por elementos avaliativos construídos também na relação imagem-texto.

\section{Construção do corpus}

A coleta de dados para este trabalho ocorreu entre os dias 18 e 22 de outubro de 2018, período próximo à data do segundo turno das eleições presidenciais no Brasil, e contou com a ajuda de ferramentas computacionais, mais especificamente o software RStudio. Em linguagem computacional $\mathrm{R}$, foi utilizado o pacote rtweet, que permite acesso à plataforma Twitter, tornando possível a coleta dos tuítes de interesse para a pesquisa. A busca ocorreu em \#FolhaPutinhadoPT devido à repercussão dessa hashtag nas mídias sociais no dia da publicação da matéria da Folha de S. Paulo sobre empresários estarem patrocinando disseminação de fake news no WhatsApp para favorecer o candidato Jair Bolsonaro.

Como resultado, obteve-se 99 comentários e optou-se por excluir os tuítes repetidos, já que estes somariam quantitativamente e poderiam distorcer a visão geral da avaliatividade. Do mesmo modo, para as análises linguísticas qualitativas, os comentários repetidos também não são significativos. Após essa filtragem, chegou-se ao número de 44 comentários a serem analisados.

Entre os comentários, notou-se que a avaliação fazia referência às seguintes categorias:

1. Folha de S. Paulo e outros veículos de comunicação (Globo, UOL etc.);

2. PT, Lula e seus apoiadores;

3. Jair Bolsonaro e apoiadores, que muitas vezes apareceram como recurso contraargumentativo para a matéria vinculada pela Folha de S. Paulo ou ainda como meio para tentar anular o adversário político, o PT.

Vale ressaltar que os comentários coletados foram feitos na época do segundo turno das eleições presidenciais, em que já se sabia que o oponente era Fernando Haddad. No entanto, este foi citado apenas uma vez, enquanto o ex-presidente Lula apareceu citado em nove tuítes, mais de uma vez em cada um.

Os comentários que serão aqui transcritos (do ex. 01 ao ex. 09) são fiéis aos dados coletados. Nenhuma correção foi realizada, a fim de preservar as características linguísticas próprias das mídias sociais. Em caso de retuíte, a menção aparecerá como “@<nome>” para se manter o anonimato do autor da postagem. 


\title{
4. Resultados e discussões
}

Quanto à análise dos textos verbais, segundo o sistema de Avaliatividade, excluindose da contagem a avaliação implícita da própria hashtag pesquisada ${ }^{4}$, foram obtidos os resultados descritos a seguir.

A respeito da categoria 1 (Folha de S. Paulo e outros veículos de comunicação), houve dois julgamentos predominantes, que apareceram em 21 dos 44 comentários: propriedade e veracidade. $\mathrm{Na}$ visão dos autores dessas postagens, o primeiro estaria fortemente ligado à corrupção; já o segundo, à produção de fake news contra Bolsonaro. Na construção de alguns comentários, é perceptível um tom de ódio, revelando ainda sentimentos de infelicidade e insatisfação.

\begin{abstract}
ex. 01: No mínimo vão FABRICAR as "provas" no dia 27 pra não dar tempo de serem contestadas, achando que brasileiro tem selo de otário na testa pra cair em grito de agonizante de jornalismo vendido. \#TodosComBolsonaro \#CadeAProva \#FolhaFakeNews \#FolhaPutinhaDoPT

ex. 02: Indignada, chega dessa imprensa corrupta. Não precisamos de dinheiro algum. \#FolhaPutinhaDoPT \#MarqueteirosDoJair

ex. 03: quem propaganda a mentira não pode receber dinheiro suado do povo brasileiro \#FolhaPutinhaDoPT

ex. 04: \#FolhaPutinhaDoPT \#FolhaFakeNews \#GloboLixo \#GloboNewslixo \#uollixo. Algumas das mídias comunistas do Brasil, a hora de vcs estão chegando vai secar a teta!!! \#BolsonaroSim
\end{abstract}

No ex. 01, os termos fabricar provas e jornalismo vendido colocam em xeque a honestidade da Folha de S. Paulo. Destaque para o processo material fabricar, em caixa alta, atribuindo força à suposição enunciada, e para a palavra prova entre aspas, já que provas não são fabricadas. A expressão grito de agonizante (sic.) revela uma possível insegurança desse jornal em relação à vitória de Bolsonaro (supondo que estariam mais preocupados com o dinheiro que iriam deixar de receber do governo). No ex. 02 é revelado um sentimento de insatisfação refletido, sobretudo, nas palavras indignada e chega. O julgamento de propriedade está instanciado na palavra corrupta. No ex. 03 há afeto de insatisfação - não pode receber dinheiro suado do povo - partindo da hipótese de que a Folha de S. Paulo recebe dinheiro público e, como é a população que paga impostos, ela não quer esse dinheiro investido em mídias que, supostamente, apoiam o candidato adversário. O julgamento quanto

\footnotetext{
${ }^{4}$ Como a pesquisa foi feita por essa hashtag, ela apareceu em todos os comentários e isso poderia afetar o levantamento quantitativo. Já a análise qualitativa será feita no ex. 09.
} 
à veracidade da notícia publicada está expresso na palavra mentira. Já no ex. 04 há um questionamento quanto à veracidade no uso da hashtag \#FolhaFakeNews, presente em onze tuítes. Como no exemplo anterior, o autor também foca no possível recebimento de dinheiro público - vai secar a teta!!! -, demonstrando uma insatisfação com a situação atual e uma satisfação com a situação futura, após vitória de Bolsonaro, atribuindo a este um julgamento (positivo) de capacidade. A palavra comunista passou a ser associada a tudo que é contra o candidato Bolsonaro, reforçando a polarização política. Aqui ela aparece para demonstrar ódio (afeto - infelicidade) e ao mesmo tempo questiona a honestidade da Folha (insinuando que ela defende a esquerda). Implicitamente, desperta um sentimento de insegurança, visto que o comunismo é posto como o inimigo a ser combatido. $\mathrm{O}$ destaque para essa postagem é o uso do plural em mídias comunistas, englobando outros meios de comunicação além da Folha de S. Paulo, tais como os expressos nas hashtags: \#GloboLixo \#GloboNewslixo \#uollixo. Assim, sugere-se que essas mídias apoiam a esquerda, consequentemente são comunista e devem ser evitadas. A palavra lixo intensifica o não-gostar.

Na categoria 2 (PT, Lula e seus apoiadores), o afeto infelicidade foi predominante juntamente com o julgamento de propriedade, semelhante ao resultado obtido na pesquisa de Lima-Lopes, Mercuri e Gabardo (2020). Neste trabalho, bem como em outros (MERCURI; LIMA-LOPES, 2020; CESARINO, 2020), observa-se nas mídias sociais uma exploração do antagonismo político, eixo amigo-inimigo, cuja estratégia é atacar adversários para se promover ou, ainda, defender-se de acusações. Os exemplos do 05 ao 07 retratam essa situação.

ex. 05: \#MarketeirosDoJair Entendam: Pela primeira vez os esquerdopatas não consegue infringir sua estratégia subversiva. Isso é mérito do povo que acordou e há de exorcizar esses demônios da vida pública. \#FolhaPutinhaDoPT \#CadeAProvaFolha

ex. 06: \#NasRuasComBolsonaro \#b17 \#MarketeirosDoJair \#FolhaPutinhaDoPT \#PTnão \#PTNUNCAMAIS \#LulaTaPresoBabaca \#LulaCondenado

ex. 07: Aguarde e confie. Toda corja política será enterrada ou presa q nem o chefe da quadrilha comunista. \#Osistemaagoniza \#NasRuasComBolsonaro \#LulaTaPresoBabaca \#FolhaPutinhaDoPT \#GloboLixo

O ataque ao adversário apareceu muitas vezes em forma de hashtag - \#PTnão \#PTNUNCAMAIS \#LulaTaPresoBabaca \#LulaCondenado - ou indiretamente (chefe da quadrilha comunista), destacando a palavra chefe como um recurso de gradação: pertencimento a um grupo e, ainda, o mais importante dentre todos. Destaque para o ex. 05, em que há uma elevação no tom, e expressões de afeto e julgamento são graduadas com a 
escolha vocabular: neologismo (esquerdopata), epíteto (subversiva), nome (demônios) e processo (exorcizar). Nesses exemplos, nota-se que o sentimento de não-gostar é potencializado, transformado em algo maior, como ódio ou raiva. Ao mesmo tempo, ao se escolherem esses termos, cria-se uma insegurança no leitor, gerando uma atmosfera de guerra iminente, cujo inimigo já foi declarado, inclusive com apelação religiosa (anjos vs. demônios). A voz passiva será enterrada (ex. 07) reforça o desejo de eliminar o inimigo, também intensificando o não-gostar. Os itens lexicais utilizados - preso, condenado, corja, quadrilha - reforçam a associação PT-corrupção.

A categoria 3 (Bolsonaro e seus apoiadores), que já apareceu em quase todos os exemplos citados anteriormente, sobretudo em forma de hashtag: \#MarketeirosDoJair, \#NasRuasComBolsonaro, \#b17, \#TodosComBolsonaro, \#BolsonaroSim, expressa afeto do tipo felicidade e, "como é comum nesse tipo de sentimento, parece não se estabelecer um processo argumentativo que justifique a relação de afeto" (LIMA-LOPES; MERCURI; GABARDO, 2020, p.18). A contra-argumentação para os fatos apresentados pela Folha de S. Paulo veio, portanto, como acusações ao jornal ou aos adversários e como utilização de hashtags de apoio, o que torna empobrecida a discussão política nessas plataformas.

Depois da análise dos textos verbais dos tuítes, foi feita a análise em textos multimodais (texto e imagem). Dos quarenta e quatro comentários analisados, apenas nove continham imagem. A escolha das imagens para a análise foi baseada na melhor representatividade para as categorias de análise pré-estabelecidas e de acordo com o espaço para a descrição neste artigo. Assim, chegou-se a duas ${ }^{5}$ imagens: uma que faz referência ao apoio a Jair Bolsonaro, e outra que expressa posição avaliativa em relação ao PT e à Folha de S. Paulo, simultaneamente.

Como mencionado alhures, uma das táticas utilizadas para contra-argumentar a matéria da Folha de S. Paulo sobre o fato de a campanha de Jair Bolsonaro usar "caixa 2" para financiar disparos de fake news, via WhatsApp, foi defender e pedir apoio ao candidato. A seguir, um retuíte de uma postagem nesse sentido, com o texto verbal (ex. 08) e a imagem a ele associada (Figura 2).

\footnotetext{
${ }^{5}$ As Figuras 2 e 3 são oriundas do Twitter e fazem parte da base de dados desta pesquisa. 


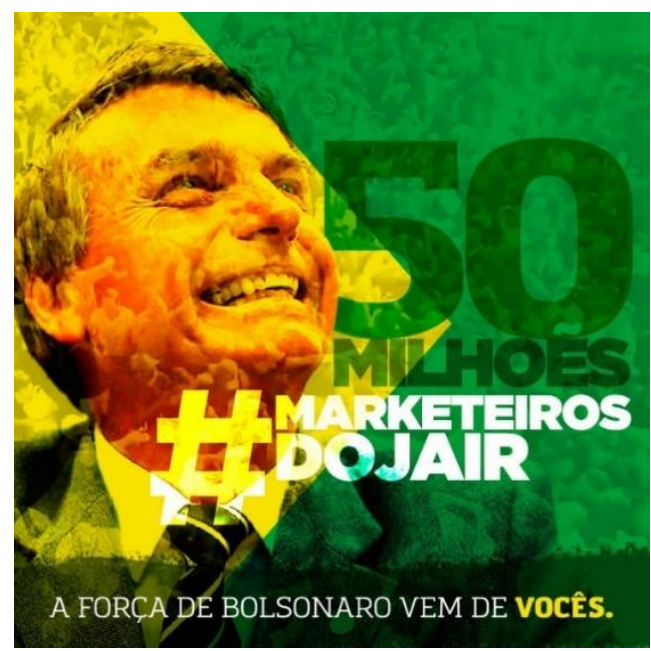

Figura 2 - apoio a Jair Bolsonaro

ex. 08: \#MarketeirosDoJair \#semmedo \#semnadaaesconder \#FolhaPutinhaDoPT @ <nome> Meu pai leva a facada, não morre por milagre de Deus e é acusado de propagar o ódio. Ele é a maior vítima de Fake news e é acusado de propagar mentiras. Nós temos o que eles não têm: vocês \#MarqueteirosDoJair

No exemplo 08, há uma tentativa de transformar o acusado pela matéria da Folha de S. Paulo em vítima, invertendo-se a normalidade dos fatos. Isso pode ser identificado no emprego das expressões: leva a facada; é acusado; maior vítima, na postagem original, endossadas pelas hashtags: \#semmedo \#semnadaaesconder, no retuíte. A força fica por conta da repetição de é acusado, que aparece duas vezes no texto, e da palavra maior antecedendo vítima. Também é questionada a veracidade do jornal, invertendo-se novamente a normalidade: o candidato fala e propaga verdades, enquanto o jornal publica fake news sobre ele. Nota-se, ainda, que a hashtag \#MarqueteirosdoJair é vocativo na última oração e tem valor interpessoal em relação ao interlocutor, vocês.

A representação na Figura 2 é conceitual, com foco no processo simbólico em que a foto do candidato aparece inserida no verde-amarelo da bandeira nacional. Vale lembrar que o uso dessas cores e da própria bandeira do Brasil tornaram-se símbolos da direita - e da extrema-direita - desde a época do impeachment da presidente Dilma Rousseff ${ }^{6}$, em oposição à cor vermelha associada ao PT. A escolha de um plano fechado e o ângulo frontal (corpo do participante) foram assim construídos para proporcionar ao leitor uma sensação de intimidade e de envolvimento. Da mesma maneira, o fato de o participante estar no mesmo nível do olhar no leitor (eixo vertical) quebra uma possível hierarquia (poder), proporcionando igualdade, o

\footnotetext{
${ }^{6}$ Como exemplo, podem-se observar as vestimentas dos manifestantes no protesto nacional contra o governo Dilma, em 2016.
} 
que reforça o marketing de campanha que o colocava como "homem do povo". Quanto à diagramação, a foto do candidato, à esquerda, constitui o Dado, algo já conhecido, e \#marketeirosdoJair é a informação nova, o Novo, criado para quebrar a audiência da matéria da Folha de S. Paulo. No eixo vertical, há a frase A força de Bolsonaro vem de vocês, em um plano mais escuro, que representa o Real, em oposição ao Ideal logo acima: 50 milhões \#marketeirosdoJair, que atuam seja disseminando a hashtag, seja participando de manifestações nas ruas, situação retratada em segundo plano.

Os elementos da imagem estão interligados, considerando o plano de fundo, a foto do candidato e a bandeira nacional, insinuando uma estreita relação entre Brasil-Bolsonaro-povo, efeito também proporcionado pela coordenação de cores, verde-amarelo, uniformizando todos os elementos. Percebe-se que há a intenção de salientar a foto do candidato em primeiro plano, direcionando o olhar do leitor, o que também serve como foco para a palavra "Jair" à qual a hashtag se refere. A palavra vocês ganha destaque de cor, e sua força vem tanto do numeral, 50 milhões, como do plano de fundo, em que há uma repetição de elementos representacionais, intensificando a quantidade de pessoas.

Pela expressão facial do candidato na foto, percebe-se uma expressão de felicidade, talvez para convencer o leitor de que, se ele espalhar a hashtag ou se juntar em manifestações, deixará o candidato feliz. Também há um julgamento implícito de estima: a normalidade de um brasileiro é apoiar esse candidato, visto que é ele que carrega as cores do país. Nesse caso, a escolha das cores tem um papel modalizador. Pode-se dizer que, nessa postagem, a imagem serve como um recurso de gradação, tanto de força - pela repetição de \#marqueteirosdoJair ${ }^{7}$ e da palavra vocês, que aparecem no texto verbal e na imagem - como de foco, pois a imagem funciona como um apelo visual para a última frase da postagem: Nós temos o que eles não têm: vocês \#MarqueteirosdoJair.

A próxima postagem não é rica em conteúdo verbal, visto que é composta apenas pelo uso de duas hashtags (ex. 09), porém a imagem (Figura 3) criada para compor o todo vai além de uma simples ilustração: ela reforça o julgamento expresso nessas hashtags.

ex. 09: \#FolhaFakeNews \#FolhaPutinhaDoPT

\footnotetext{
${ }^{7}$ Grafado \#marketeirosdojair na Figura 2. 


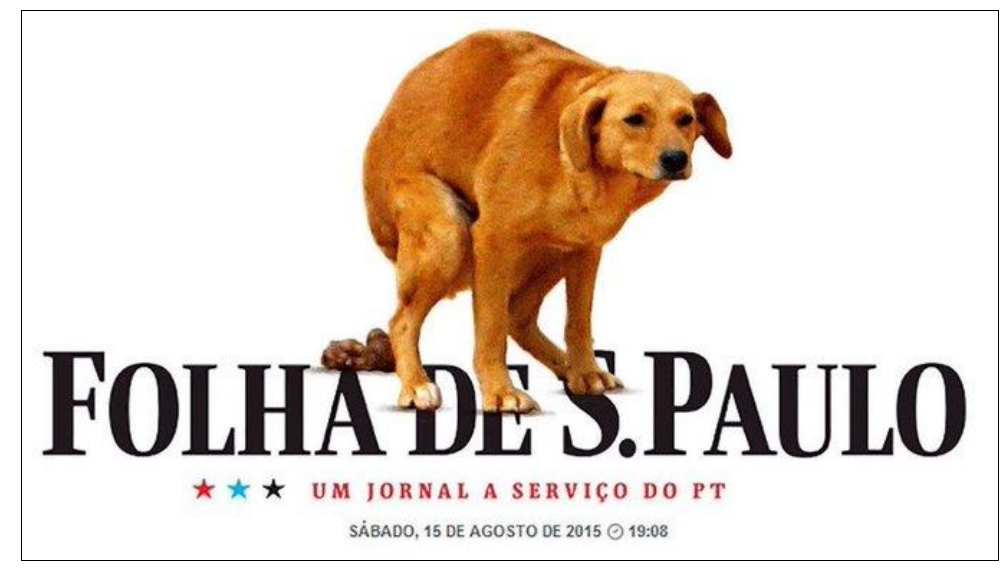

Figura 3 - Folha de S. Paulo e PT

No texto verbal do ex. 09, analisando primeiramente a hashtag \#FolhaFakenews, há um julgamento de veracidade, pois é questionada a situação trazida pela Folha de S. Paulo como sendo não um fato (news), mas sim algo forjado (fake). Já a hashtag \#FolhaPutinhaDoPT - presente em todos os comentários - traz em si uma expressão de infelicidade, da ordem do não-gostar, o que se aplica tanto ao jornal quanto ao partido. Ao afirmar que o jornal é a "putinha” do partido, é julgada a ética do jornal, insinuando que ele publica o que o PT paga para ser publicado e, portanto, é parcial. Indiretamente, também seria uma forma de questionar a veracidade das publicações da Folha, na tentativa de persuadir o leitor não só a não acreditar em tais notícias, mas também a deixar de ler as publicações desse veículo de comunicação, assim como de outros que apareceram aqui acompanhados da palavra lixo.

Na Figura 3, há uma narrativa, contada pela posição do corpo do cachorro, indicando o momento em que ele defeca. Nesse processo de ação transacional, o cachorro é o ator e a Folha de S. Paulo é a meta, aquela que é afetada. A impessoalidade (sem contato visual entre leitor e representado) e o distanciamento (posicionamento do corpo do cão em relação ao leitor) mostram que o foco não é o cachorro em si, mas sim sua atitude. $\mathrm{O}$ valor da informação está pautado na distribuição Centro-Margem dos elementos: a atitude do cão está centralizada em relação ao título do jornal. Os elementos estão interligados, sem qualquer moldura; há inclusive uma preocupação em colocar as patas do cachorro intercruzando as letras do título do jornal e as fezes sendo deixadas em cima dessas letras. Nota-se também a escolha de um cachorro sem raça definida, com cor de caramelo, muito popular nas ruas do Brasil, o que pode conotar um desapreço ainda maior ao jornal. Devido ao tamanho desse elemento em relação aos demais, ele é considerado o mais saliente e, juntamente com a sua posição central, atrai o olhar do leitor. Nessa imagem, o elemento verbal também deve ser 
analisado: há manutenção da tipografia, data e hora, característicos do jornal. No entanto, o subtítulo: Um jornal a serviço do Brasil foi trocado por: Um jornal a serviço do $P T$, a fim de ratificar o dito no texto da postagem (ex. 09). Além disso, como o texto original estava escrito na cor $\operatorname{preta}^{8}$, que na imagem foi propositalmente trocada pela cor vermelha, pode-se inferir que há uma relação com a cor do Partido dos Trabalhadores, na tentativa de aproximar o jornal a esse partido. Tudo isso mostra que há uma intensificação dos dizeres pela multimodalidade (relação imagem-texto).

\section{Conclusão}

Este artigo apresentou algumas considerações acerca do discurso de ódio que acompanhou a hashtag \#FolhaPutinhadoPT no Twitter, na época da campanha eleitoral - $2^{\circ}$ turno - para presidente do Brasil, em 2018, a fim de trazer para reflexão o tratamento dado à imprensa, bem como algumas estratégias políticas.

De maneira geral, foram observados: i) a desmoralização de alguns meios de comunicação, sobretudo quando estes traziam notícias que, de alguma maneira, poderiam prejudicar o candidato apoiado pelo grupo que disseminou a hashtag pesquisada (\#FolhaPutinhadoPT); ii) ataque aos adversários políticos como mecanismo de defesa (como \#oLulaTaPresoBabaca); iii) campanha por propagação de hashtags de apoio (por exemplo, \#MarketeirosdoJair), como estratégia para contrariar e tirar o foco da notícia da Folha de S. Paulo que expunha uma rede de espalhamento de fake news e o possível uso de "caixa 2".

Quanto às ocorrências de afeto identificadas, inclusive na hashtag produzida, nota-se o ódio ao Partido dos Trabalhadores (PT) e à Folha de S. Paulo. Como forma de intensificação do não-gostar, predominou a escolha vocabular, a partir do uso de determinados processos (exorcizar, será enterrada), epítetos (comunista, subversiva, putinha, corrupto/a) e neologismos (esquerdopatas, Folhafakenews). Em relação aos julgamentos, a Folha de S. Paulo recebeu avaliações acerca de sua honestidade (veracidade) e a sua ética (propriedade), em igual proporção. Já o PT foi sempre trazido ao texto em situações que envolvessem corrupção ou prisão, fazendo com que o julgamento de propriedade prevalecesse. Isso vem sendo constatado em alguns trabalhos, o que pode induzir a um padrão de contra-ataque. Já em relação a Bolsonaro, as expressões de apoio vieram, na maioria das vezes, em formato de hashtag, ressaltando afeto (felicidade), o qual foi predominante nessa categoria.

\footnotetext{
${ }^{8}$ Levando-se em consideração as capas do jornal Folha de S. Paulo da época, outubro de 2018. 
Implicitamente, tomando as acusações feitas aos adversários, subentende-se que o candidato Bolsonaro seria o oposto, o que é típico da estratégia do populismo em centralizar a discussão no eixo amigo-inimigo, avaliando negativamente o outro para causar uma avaliação positiva de si (CESARINO, 2020). Nesse sentido, houve julgamentos de capacidade (ele seria capaz de resolver os problemas que o antecessor deixou) e de propriedade (já que o outro é considerado corrupto, este seria o ético).

Notou-se também que, em alguns comentários, a atitude avaliativa do texto verbal foi complementada com a inclusão de imagens. Foi verificado que muitos recursos gráficos presentes nessas imagens, tais como ângulos vertical e horizontal, primeiro plano, escolha das cores e tipografia, reforçaram tanto uma avaliação positiva (Figura 2) quanto negativa (Figura 3). Já a escalonação de itens, repetição de elementos representacionais semelhantes, intensificação de cor/brilho e concentração de informação visual em determinado ponto funcionaram como recursos de gradação, força e foco, com a finalidade de persuadir o leitor. Assim, pode-se dizer que houve uma relação de dependência entre imagem e texto verbal, visto que ambos foram necessários para a construção de significados avaliativos nesse contexto.

Por fim, espera-se que este trabalho traga contribuições aos estudos da Avaliatividade em textos multimodais e nas interpretações semântico-discursivas das particularidades léxicogramaticais presentes em textos de mídias sociais.

\section{Agradecimentos}

O presente trabalho foi realizado com apoio da Coordenação de Aperfeiçoamento de Pessoal de Nível Superior - Brasil (CAPES) - Código de Financiamento 001.

\section{REFERÊNCIAS}

CESARINO, L. Como vencer uma eleição sem sair de casa: a ascensão do populismo digital no Brasil. Internet \& Sociedade, [s. l.], v. 1, n. 1, p. 91-120, 2020.

CORDEIRO, A. L. Estrutura linguística da hashtag \#MeuAmigoSecreto: recursos de denúncia ao machismo no Facebook. Revista Diálogos, Cuiabá, v. 8, n. 1, p. 258-271, 2020.

DELLA COLETTA, R. Bolsonaro manda repórteres calarem a boca, ataca a Folha e nega interferência na PF. Folha de S. Paulo, 5 maio 2020. Disponível em: https://www1.folha.uol.com.br/poder/2020/05/bolsonaro-manda-reporteres-calarem-a-bocaataca-a-folha-e-nega-interferencia-na-pf.shtml. Acesso em: 05 mar. 2021. 
ECONOMOU, D. Photos in the news: appraisal analysis of visual semiosis and visual-verbal intersemiosis. 2009. 398 f. Tese (Doutorado em Filosofia) - University of Sydney, Sidney, Australia, 2009.

FLOREK, C. S. Marcas avaliativas em imagens jornalísticas. Entretextos, Londrina, v. 17, n. 2, p. 195-230, 2017.

HALLIDAY, M. A. K.; MATTHIESSEN, C. M. I. M. Halliday's Introduction to Functional Grammar. 3. ed. London: Hodder Education, 2004.

HALLIDAY, M. A. K. An introduction to functional grammar. 2. ed. London: Routledge, 1994.

HOPPER, P. J.; TRAUGOTT, E. C. Grammaticalization. Cambridge: Cambridge University Press, 1993.

IKEDA, S. N. O julgamento na argumentação de um editorial. In: VIAN JR., O; SOUZA, A. A.; ALMEIDA, F. S. D. P. (Org.). A linguagem de avaliação em língua portuguesa: Estudos sistêmico-funcionais com base no Sistema de Avaliatividade. São Carlos: Pedro e João Editores, 2010. p. 167-188.

JEWITT, C.; KRESS, G. Multimodal literacy. New York: Peter Lang, 2008.

KRESS, G.; VAN LEEUWEN, T. Reading images: the grammar of visual design. London; New York: Routledge, 1996.

LIMA-LOPES, R; MERCURI, K. T; GABARDO, M. Avaliatividade em comentários sobre postagens dedicadas à verificação de notícias falsas nas eleições presidenciais de 2018. Cadernos de Linguística, Campinas, n. 1, v. 4, p. 1-25, 2020.

LIMA-LOPES, R. E; GABARDO, M. Ni una menos: a luta pelos direitos das mulheres na Argentina e suas representações no Facebook. Revista Brasileira de Linguística Aplicada, Belo Horizonte, v. 19, n. 4, p. 801-824, 2019.

LIMA-LOPES, R. E. Sociossemiótica da produção audiovisual: uma proposta metodológica para a análise multimodal da comunicação em vídeo. 2012. 282 f. Tese (Doutorado em Linguística Aplicada) - Universidade Estadual de Campinas, Campinas, 2012.

MACEDO, K. T. M. Conflitos Sociais Contemporâneos: possíveis causas e consequências dos Linchamentos Virtuais. Humanidades \& Inovação, Palmas, v. 5, n. 4, p. 197-208, 2018.

MARTIN, J. R.; WHITE, P. R. The Language of Evaluation. v. 2. Basingstoke: Palgrave Macmillan, 2005.

MELLO, P. C. Empresários bancam campanha contra o PT pelo WhatsApp. Folha de S. Paulo, 18 out. 2018. Disponível em: https://www1.folha.uol.com.br/poder/2018/10/empresarios-bancam-campanha-contra-o-ptpelo-whatsapp.shtml. Acesso em: 19 out. 2018. 
MERCURI, K. T; LIMA-LOPES, R. E. Discurso de ódio em mídias sociais como estratégia de persuasão popular. Trabalhos em Linguística Aplicada, Campinas, v. 59, n. 2, p. 1216$1238,2020$.

MOISÉS, J. A. Democracia e confiança: por que os cidadãos desconfiam das instituições públicas? São Paulo: Edusp, 2010.

NASCIMENTO, R. G; BEZERRA, F. A. S; HEBERLE, V. M. Multiletramentos: iniciação à análise de imagens. Revista Linguagem \& Ensino, Pelotas, v. 14, n. 2, p. 529-552, 2011.

NUNES, G. G; CABRAL, S. R. S. Avaliação e ideação: acoplamentos avaliativos em editoriais. In: FUZER, C; SILVA, T. S. (Org.). Linguagem e Representações: estudos em Linguística Sistêmico-Funcional. Santa Maria: UFSM, PPGL Ed., 2017. p. 223-267.

NUNES, G. G.; CABRAL, S. R. S. Avaliatividade e julgamento: uma análise de texto. Nonada: Letras em Revista, Porto Alegre, v. 1, n. 20, p. 249-265, 2013.

SENRA, R. 'Repórter tem que apanhar mesmo': ataque de Bolsonaro gera onda de ameaças físicas a jornalistas. Terra, 24 ago. 2020. Disponível em:

https://www.terra.com.br/noticias/brasil/reporter-tem-que-apanhar-mesmo-ataque-de-

bolsonaro-gera-onda-de-ameacas-fisicas-ajornalistas, a531aaaf8ffb0932d35c82ae9d44d000ioha5023.html. Acesso em: 03 fev. 2021.

SPECK, B. O financiamento de campanhas eleitorais. In: ANASTASIA, F; AVRITZER, L. (Org.). Reforma Politica no Brasil. Belo Horizonte: Editora UFMG, 2006. p. 153-158.

THOMPSON, G.; ALBA-JUEZ, L. (Org.). Evaluation in context. Amsterdã: John Benjamins Publishing Company, 2014.

WHITE, P. Valoração - A Linguagem da Avaliação e da Perspectiva. Linguagem em (Dis)curso - LemD, Tubarão, v. 4, n. esp., p. 178-205, 2004.

ABERT. Relatório ABERT sobre Violações à Liberdade de Expressão/2020. Brasília, DF, 2021. Disponível em: https://www.abert.org.br/web/notmenu/relatorio-abert-sobre-violacoesa-liberdade-de-expressao-2020.html. Acesso em: 03 abr. 2021.

Artigo submetido em: 11 abr. 2021

Aceito para publicação em: 03 jun. 2021

DOI: http://dx.doi.org/10.22456/2238-8915.112957 